\title{
State of the Art Implementation of Automated Fire Accident Detection with Robust Control by Utilizing Industry 4.o Terminology
}

\author{
Md. Zahid Hasan ${ }^{1 *}$ (D) , Anik Baul² and Md. Ariful Islam ${ }^{1}$ \\ ${ }^{1}$ Department of Industrial \& Production Engineering, Rajshahi University of Engineering \& Technology, Rajshahi-6204; \\ Bangladesh \\ ${ }^{2}$ Department of Electrical \& Electronic Engineering, Rajshahi University of Engineering \& Technology, Rajshahi-6204; \\ Bangladesh
}

\begin{abstract}
The key work of this research is to implement the 'Fourth Industrial Revolution' by using the internet of things (IoT) which can be applied to flammable gas condition monitoring and detection of gas leakage and activate fire extinguisher in case of fire accidents. Internet of things enabled the sensors to transmit LPG concentration value reading to the mobile app or cloud server and control actuators by connecting all in the same network. In case of a fire accident, the solenoid valve will be opened automatically or can be opened by an android application manually which will be pre-installed in mobile phones. Another advantage of this system is, the gas cylinder or flammable particle source can be closed by closing the solenoid valves attached to their outlets. The first challenge of industry 4.0 is to develop a cyber-physical system where all physical entities can be monitored and controlled over the internet or another way remotely or from a single point. This fire extinguisher system can be used everywhere and in all types of fire-fighting because all types of fire extinguishers are commercially available in cylinders where solenoid valves can be used instead of conventional valves. Use of robust automatic control system will eliminate the effort of human for continuous monitoring of LPG condition, leakage and in the activation of fire extinguishers by cyber-physical system.
\end{abstract}

Keywords: Industry 4.0; IoT; LPG; condition monitoring; LPG leakage; fire extinguisher

\section{INTRODUCTION}

Industry 4.0 has become a buzzword nowadays. Smart manufacturing system, smart material handling system, smart logistic system, and smart security system etc. are given much emphasis in recent researches. "Industry 4.0 comprises a variety of technologies to enable the development of a digital and automated manufacturing environment as well as the digitization of the value chain" (Oesterreich \& Teuteberg, 2016). Industry 4.0 aims to mass digitization and automation in all possible environments of an organization as well as the creation of a digital value chain to enable the communication between products and their environment and business partners. As a result, product quality improvement, lead time minimization, mass customization of products etc. will be possible. The main features of the Industry 4.0 will be Short development periods, Individualization on demand, Flexibility, Decentralization, Resource efficiency, etc. (Weyer et. al., 2015; Hasan et al., 2020). The successful implementation of Industry 4.o relies on the Internet of Things (IoT) technology collaborate with the IT and emphasized upon three major aspects such as smooth integration of IoT sensors with the existing industrial equipment, secured communication linking the manufacturing and other data to the cloud and development of the industrial IoT architecture (Zawra et al., 2018). Industry 4.0 aims to convert the existing manufacturing and all related processes to be connected to the cloud or cyber world with the help of cyber-physical 
system or industrial IoT to analyze the real-time data and make data-driven action with the help of modern data science technologies (Xu et al., 2018).

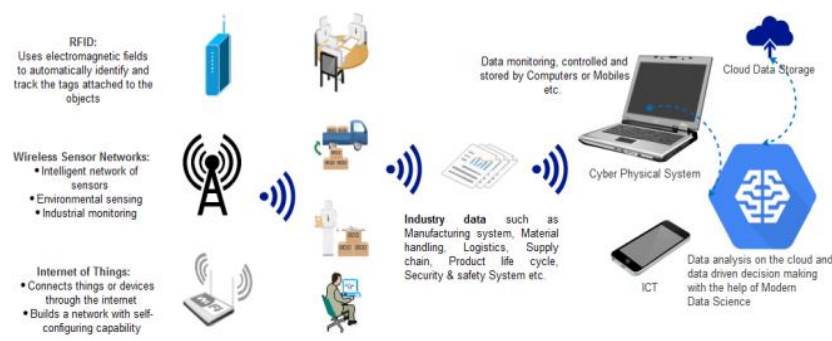

Figure 1 . Industry 4.0 and the role of IoT to build a cyberphysical system

The Internet of Things is the network of physical devices that combine IP connectivity with software, sensors, actuators, and other electronics to directly integrate the physical world into our computer-based systems, resulting in efficiency improvements and economic benefits (Minerva et al., 2015). The Internet of Things is a network of Internetconnected devices that communicate embedded sensor data to the cloud for centralized processing to build intelligent systems (Zhu et al., 2010). There are two primary parts of the IoT: the connection of devices \& sensors and another is the cloud server where sensors collect \& store the data for further processing (Ghayyur et al., 2018). The device part is a combination of the circuit made of many sensors which collect data at the predefined interval with the help of internet connection automatically and the cloud stores data as a properly structured database (Atzori et al., 2010). There are many challenges in data mining \& communication between devices \& cloud. The devices should be unobtrusive, able to connect to the internet, small in size, need very less power, able to store data at the set interval, able to provide a rudimentary failure signal. The collected data can be used for machine learning or forecasting as well as to build intelligent \& smart systems (Ray, 2018). The internet of a thing consists of four layers or works in four stages: sensing layer (collects data from the sensor), network layer (measures and transmits data to the processing unit via Bluetooth, $\mathrm{Wi}-\mathrm{Fi}$, radio signals etc.), data processing layer (AI, cloud computing, big data analysis etc.) and the application layer (required action, control, data storage, decision making etc.) (Khan et al., 2012).

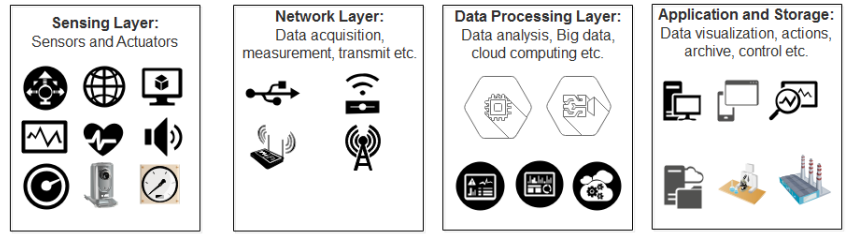

Figure 2. The IoT architecture consisting of four layers/stages

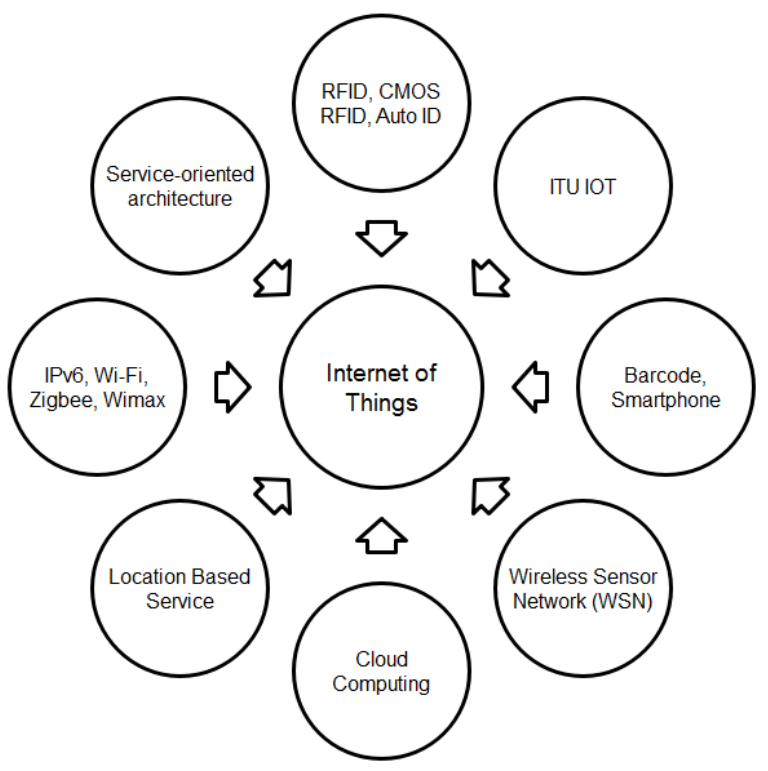

Figure 3. Technologies and networks supporting the IoT

LPG ((liquefied petroleum gas) consists of a mixture of propane and butane, which is a highly flammable chemical. It is an odourless gas, due to which Ethanoate oil is added as powerful odorant so that leakage can be easily detected. There are other international standards like EN589, amyl Mercaptan and Tetrahydrothiophene which are most commonly used as odorants. LPG is one of the alternative fuels used nowadays. LPG is also used as an alternate fuel in vehicles due to soaring the prices of petrol and diesel. In most of the countries supply, LPG or cylinder LPG is used for cooking. LPG is vastly used in hospitals, food, pharmaceuticals, machinery and many clothing industries also. LPG is a highly flammable chemical and also very dangerous because every year many fire accidents occur due to LPG leakage and also causes the death of people. Most of the fire accidents or explosions occur due to the leakage of the LPG from the cylinder and the contact with heat or any fire source like fire matches.

This research presented an Internet of Things based LPG condition monitoring, fire detection and extinguisher system 
both for home and industrial application. Implementation of Industry 4.0 is necessary to achieve a cyber-physical system in every sector of the industry. A fire safety system is a vital part of any industry and by implementing Industry 4.0, it will be possible to reduce the fire accident rate to $0.00 \%$. This is because continuous condition monitoring can help to take rapid actions and the cyber-physical system can make it possible. Even automatic activation of the fire extinguishing system without deploying any person is possible by the successful implementation of industry 4.o, which has been discussed in this research.

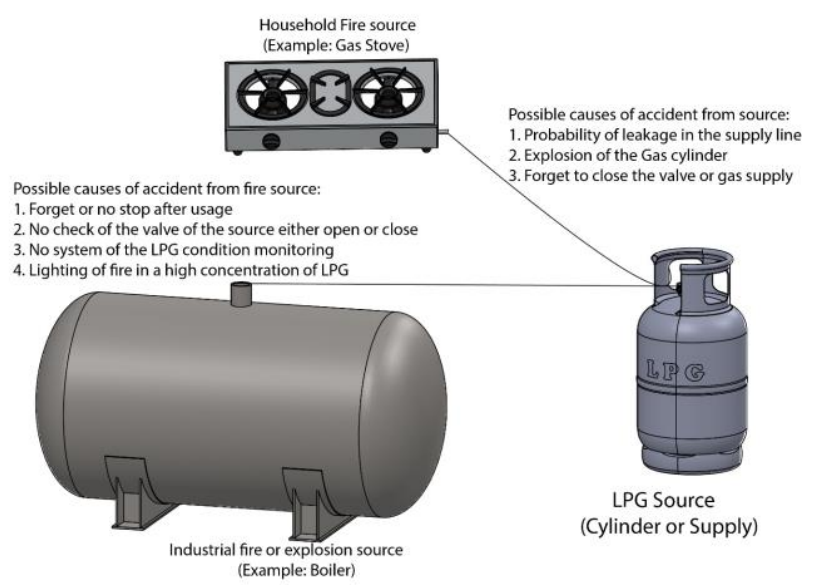

Figure 4. An overview of fire accident from LPG

\section{LITERATURE REVIEW}

Industry 4.0 is one of the most recent concepts introduced to the world in 2011 first and many industries across the globe have started research to gradually implement it into every sector. There is no literature directly the implementation of industry 4.0 in the fire system but some research are found on the application of the internet of things in LPG condition monitoring and leakage detection.

\begin{tabular}{lll}
\hline Year & \multicolumn{1}{c}{ Key Findings } & Reference \\
\hline 2010 & Fabricated p-polyaniline/n-ZnO & (Dhawale et \\
& thin-film heterojunction sensor & al., 2010) \\
& for LPG detection which & \\
& exhibited maximum response of & \\
& 81\% upon exposure of 1040 ppm \\
& of LPG.
\end{tabular}

2011 Developed a gas leakage detection with wireless sensor

(Chengjun et network (WSN) to detect the leakage point with the overall system design.

2017 Proposed and analyzed a roadmap approach to achieve smart logistic processes in realtime speed, high accuracy, and flexibility in the context of industry 4.0 using the internet of things.

2017 Used IoT interfacing MQ-2(gas sensor), LM 35(temperature sensor with microcontroller to detect the LPG level, leakage etc.

2018 Discussed and analyzed the application of internet of things in firecrackers industry for fire safety precaution and prevention with related sensors and actuators.

2018

Developed a wireless sensor network system using MQ-6 gas sensor and wireless module Bluetooth HC-O5 with Arduino to detect gas leakage and neutralize it.

2018 Analyzed the utilization of internet of things to implement industry 4.0 as IoT helps to receive continuous data about conditions and other factors from the supply chain, logistics, process etc. by converting things physical data into signals and transmitting to computers or cloud.

2018 Applied a novel multi-criteria decision making to find the main obstacles in implementing industry 4.0 in leather processing industries and developed a successful way to make proper decisions about it.

2019 Developed a local IP based environment condition such as LPG concentration system with MQ-6 sensor by developing a
(Trappey et al., 2017)

(Keshamoni

\& Hemanth, 2017)

(Savitha \&

Malathi, 2018)

(Dewi \&

Somantri, 2018)

(Zawra et al., 2018)

(Moktadir et al., 2018)

(Mallik et al., 2019) 
wireless sensor network without any internet.

Developed an IoT based LPG leakage monitoring system with the help of integrating sensors and servers and interfacing with a microcontroller to control it by feedback and feed-forward control system.

Developed LPG leakage monitoring system using IoT and mechatronic system to the engine chamber/ fuel chamber of the modern marine vessels using dual-fuel power cycle with LPG/LNG as secondary fuelflamer.

The recently published articles related to IoT and Industry 4.0 did not focus the implementation of Industry 4.0 in the household and industrial fire safety system so that the LPG leakage or even any fire can be detected and extinguished remotely and rapidly. The recent articles of LPG leakage and condition monitoring just developed the system with sensors, communication technology, servers and control system but no one focused upon the practical implementation in residential houses or industries with developing the proper cyber-physical system as a successful transition to industry 4.0.

\section{MATERIALS AND METHODOLOGY}

\section{A. System Architecture}

Hardware Components:

- $\quad$ NodeMCU v2

- $\quad$ Toxic Gas Sensor Module MQ-6

- DHT-11 Sensor

- $\quad$ Solenoid Valve (12V)

- 300 Mbps Router

- Battery

- Jumper Wires

- Relay Modules etc.

Specifications:

- Voltage:3.3V.

- Wi-Fi Direct (P2P), soft-AP.

- Current consumption:

Figure $5 . \quad$ 10uA $170 \mathrm{~mA}$.

NodeMCU

(Controller)

- $\quad$ Flash memory attachable: $16 \mathrm{MB}$ $\max (512 \mathrm{~K}$ normal).

- Integrated TCP/IP protocol stack.

- Processor: Tensilica L106 32-bit.

- Processor speed: 80 16oMHz.

- $\mathrm{RAM}: 32 \mathrm{~K}+80 \mathrm{~K}$.

- GPIOs: 17 (multiplexed with other functions).

- Analogue to Digital: 1 input with 1024 step resolution.

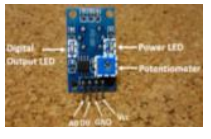

Figure 6.

MQ-6 gas

sensor

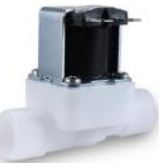

Figure 7. 12

V DC

solenoid

valve
Specifications:

- Concentration level of it is from $200-1000 \mathrm{ppm}$

- The sensitive material of MQ-6 is tin dioxide $(\mathrm{SnO} 2)$

- Detects the following flammable gases: 1. Propane, 2. Hydrogen, 3. Methane, 4. Butane.

- $\quad$ Circuit and Heating voltage $5 \pm 0.1$ V

Specifications:

- $\mathrm{APL}-3 / 2 "-12 \mathrm{VDC}$

- Position: Normally Closed

- $\quad$ Port Size: $1 / 2 "$ Male NPT

- Voltage: $12 \mathrm{~V}$ DC

- Body Material: POM Plastic

- Orifice Size: $8.5 \mathrm{~mm}$

- Temp Range: 32 to $125^{\circ} \mathrm{F} /$ o to $50^{\circ} \mathrm{C}$

- Power: 6 Watts

An experimental setup was prepared with the controller, relays, sensors and actuators interfacing with the mobile app and online server. Figure 8 and 9 show the prototype for the experimental analysis of the system. 


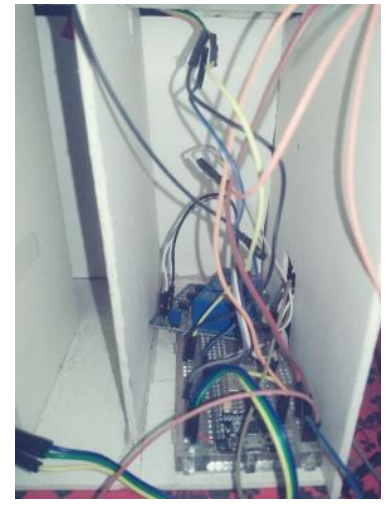

Figure 8. Controller and

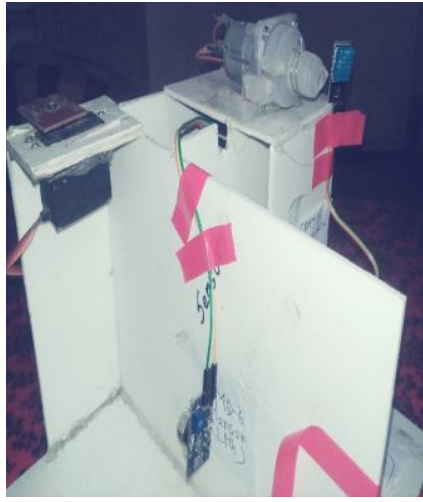

Figure 9. Sensors and

Actuators

\section{B. Working Algorithm}

The LPG ppm, temperature etc. are sensed by the gas sensor MQ-6, DHT-11 and transmit the information to the controller by that firstly it switches ON the relay and buzzer to give the alertness in the industry or home. If it continues again, check the threshold gas value and sends the message to the user via the mobile app and online server. To prevent gas leakage accidents, the solenoid valves will be activated automatically. The LPG ppm threshold value can be set arbitrarily as a requirement and area of use. Generally, the average ppm value is $1040 \mathrm{ppm}$ that may cause explosion or fire accidents. The LPG ppm and other sensor values can be stored automatically into the online server and monitored via both mobile app and server. Both automatic and manual action is possible in this system.

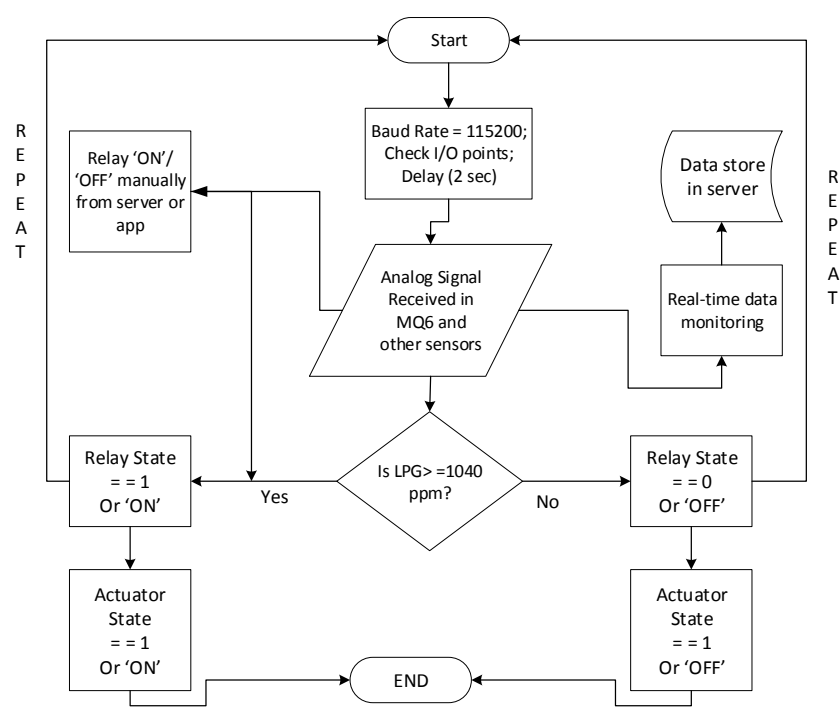

Figure 10. Working flowchart of the system
Figure 11 represents a practical connection of single LPG cylinder and single $\mathrm{CO} 2$ cylinder for general household fire safety system of this proposed system. Solenoid valves can be controlled with electrical signals so that the cylinders existing valves will be replaced by solenoid valves. The gas sensor will be set close to the cylinder or source. Also, the DHT-11 sensor can be set close to the stove where fire exists generally. The solenoid valves will be connected with the controller with the help of relays and DC batteries will supply power to the solenoid valves. The controller and Wi-Fi router will get power supply from the DC source because continuous power supply must be ensured even during load shading. The mobile and computer have to be connected to the same router and the real-time LPG ppm value, temperature, humidity can be monitored with the help of IoT. The solenoid valve can also be manually controlled via mobile or computer server by changing the states of the relays (Relay $==0==$ 'OFF'; Relay $==1==$ 'ON'). Also, the program uploaded in the controller can automatically turn 'ON' or 'OFF' the actuators when the threshold value of ppm exceeds in the room. The sensor data can also be stored to the cloud server.

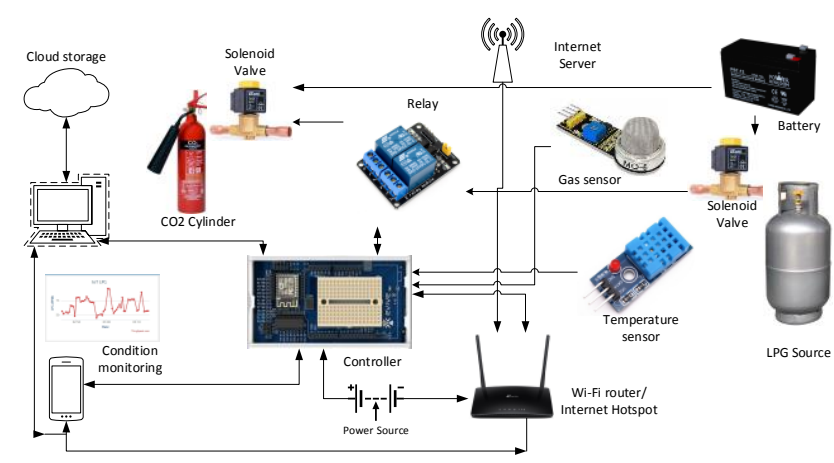

Figure 11. Working flowchart of the system

\section{Practical Setup}

In a real implementation, the actuators are solenoid valves, which will be controlled via the Internet of Things and mobile app. The Carbon dioxide cylinder will be set near the stove and a solenoid valve will attach to the outlet of the $\mathrm{CO}_{2}$ cylinder. In case of any fire accident, the solenoid valve can be opened and $\mathrm{CO}_{2}$ spray will be possible by pressing the button in the mobile app (Virtuino). Another solenoid valve will be attached to the outlet of the LPG cylinder or the supply port. If any leakage is detected or the LPG concentration exceeds $1040 \mathrm{ppm}$, then either the solenoid valve will 
automatically be closed or it can be closed via the mobile app with the help of internet of things (IoT). The control box contains the controllers and relays. The MQ6 sensor will be set close to the LPG cylinder or supply source. Figure 12 illustrates the practical arrangement of the system. Electrical wire connections have been ignored here.

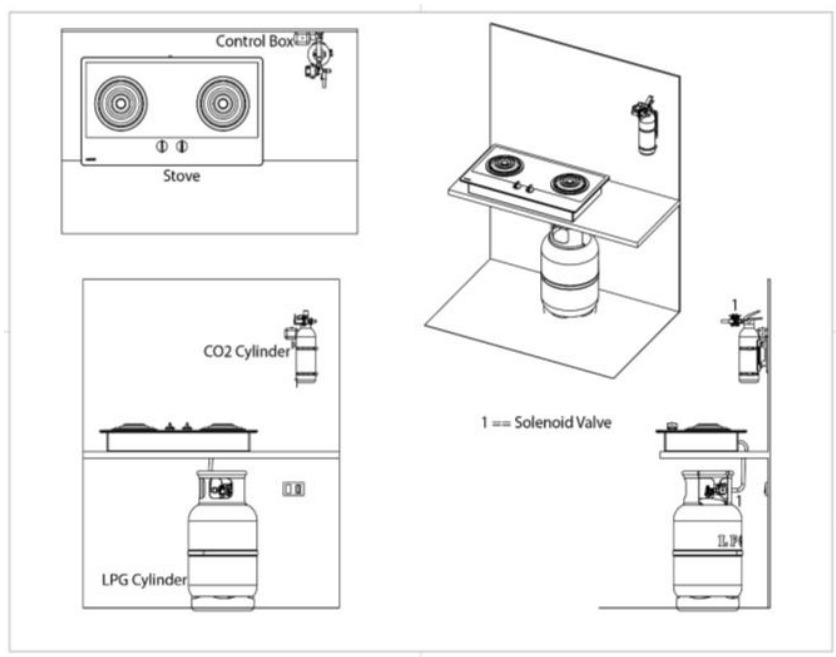

Figure 12. Fire extinguisher system arrangement for residential kitchen

The industrial setup in real implementation will be very complex because there many $\mathrm{CO} 2$ cylinders and Solenoid valve will be required. Every fire extinguisher cylinder has a certain range to deploy the material or gas. So the cylinders should be placed depending upon the range one after another. Also, the valves have to be connected in series or parallel according to the need and type of the industrial operation and safety system. A general boiler room layout has been represented in Figure 13. The red marked area shows where the MQ-6 sensor and Fire extinguisher cylinders are required to implement the proposed industry 4.0 in the safety system of the boiler room.

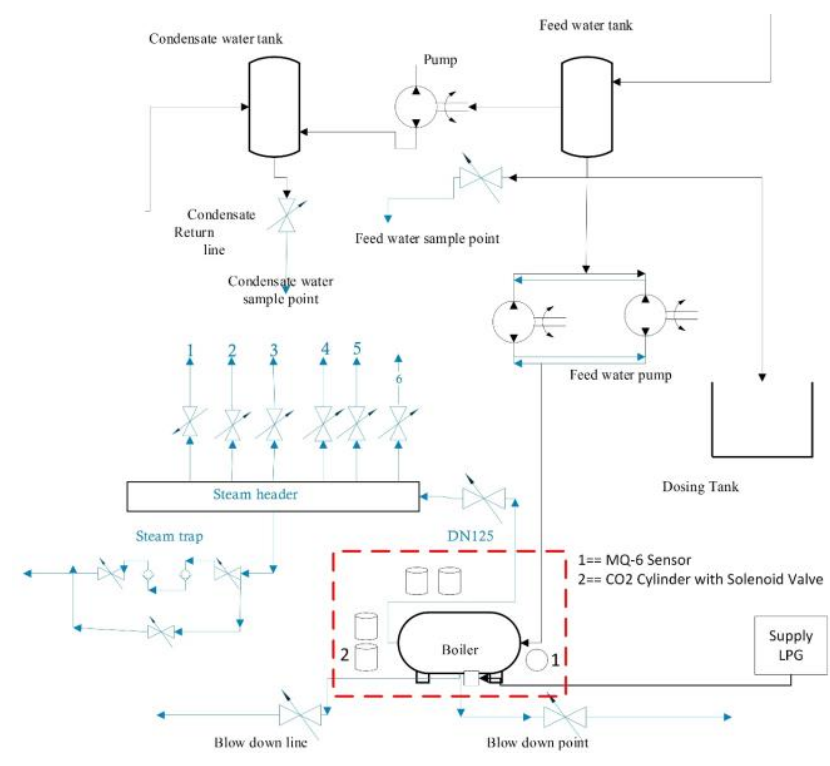

Figure 13. A practical setup concept in a boiler room

Figure 14 represents a common LPG supply from commercial vendors in Bangladeshi industries. After receiving the gas from the Vendor Company, it is stored into a gas header in the RMS room. From the header two pipelines are divided. The colour of one line is yellow and another is blue. Each pipeline has some valves for controlling the flow and pressure of gas and a flow meter is attached for measuring the flow of gas. In each line, there are two ball valve, one safety valve, one strainer, one filter and a flow meter. The yellow pipe goes to the gas generator head and the blue goes to the boiler head. From generator head, two-line goes to two generators. From boiler head, one subline goes to the production floor and another goes to the boiler. 


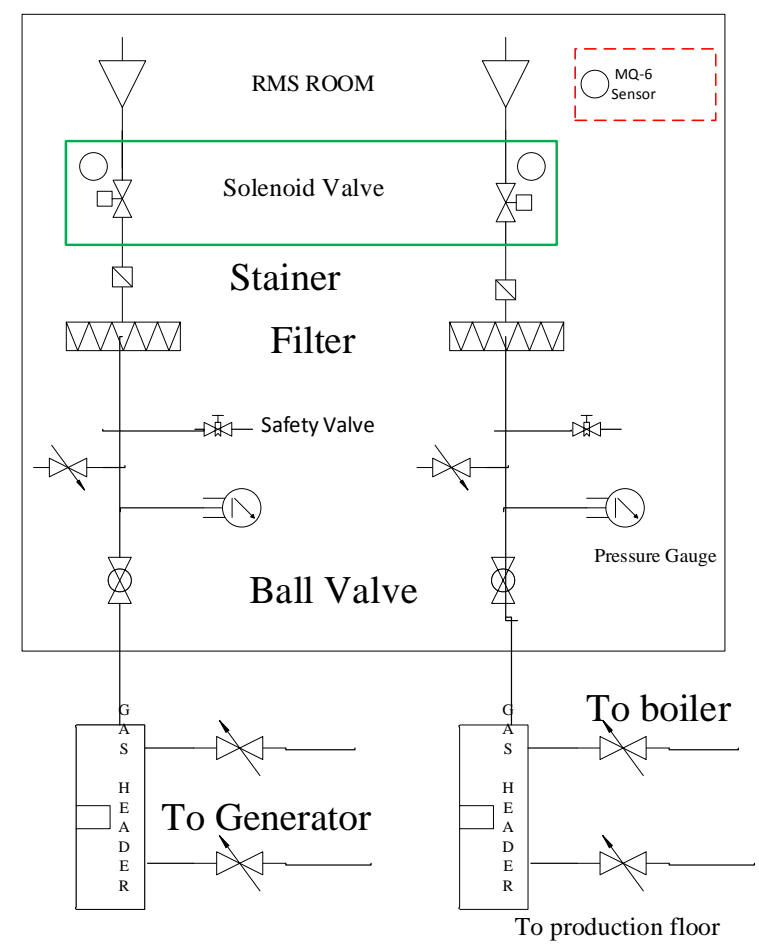

Figure 14. A common LPG supply block diagram in the industries

The ball valves can be replaced with solenoid valves and some MQ-6 sensors can be installed close to the valves so that the LPG ppm can be monitored continuously in the main LPG supply control room. The main supply control room is the most vital point in fire-fighting and also eliminate the waste of LPG.

\section{RESULTS AND DISCUSSION}

\section{A. Result from Prototype \\ 1. Mobile App Interface}

The mobile application interface can be seen from Figure 15 and 16. First, the mobile has to connect with the same router or internet network where the controller or NODEMCU is connected. This will automatically allow the mobile application to receive the readings from the sensors and actuator command signals.

The sensors can read data after every 5 seconds and the data on the display change after 5 seconds automatically. The LPG, temperature and humidity can be monitored with mobile in this way.

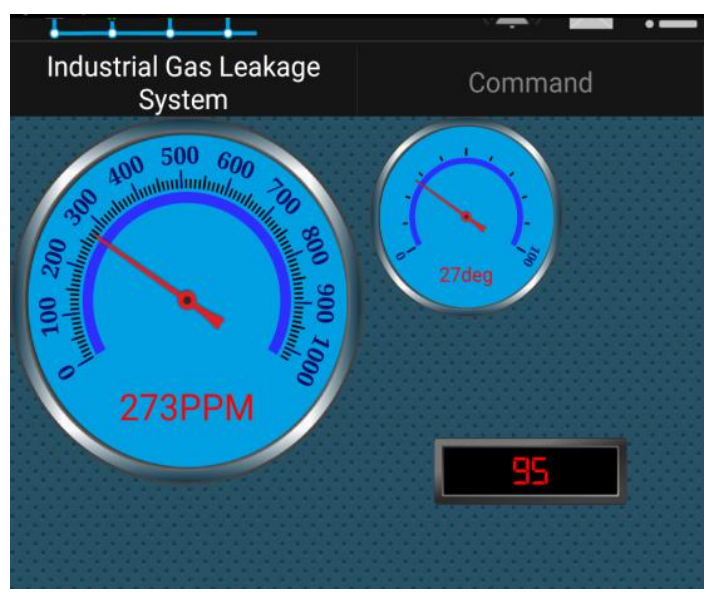

Figure 15. LPG ppm, temperature and humidity reading on the mobile application

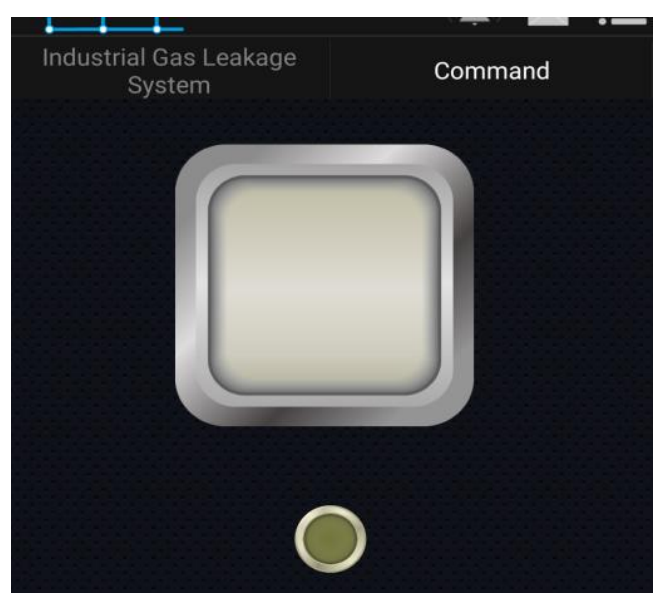

Figure 16. The actuator on/off button on the mobile application

In the case of manual control (Feed-forward), the actuators can be on/off by pushing the buttons shown in Figure 16. Actuators will not be opened if the system is set to be manually operated or feed-forward control system. Here is the main advantage of automatic (Feedback) system, because the actuators will be automatically activated if the LPG concentration exceeds the set threshold value and vice-versa. The mobile app can be connected or disconnected from this interface. The ppm value can be monitored or the command buttons can be controlled individually or simultaneously in this way. 


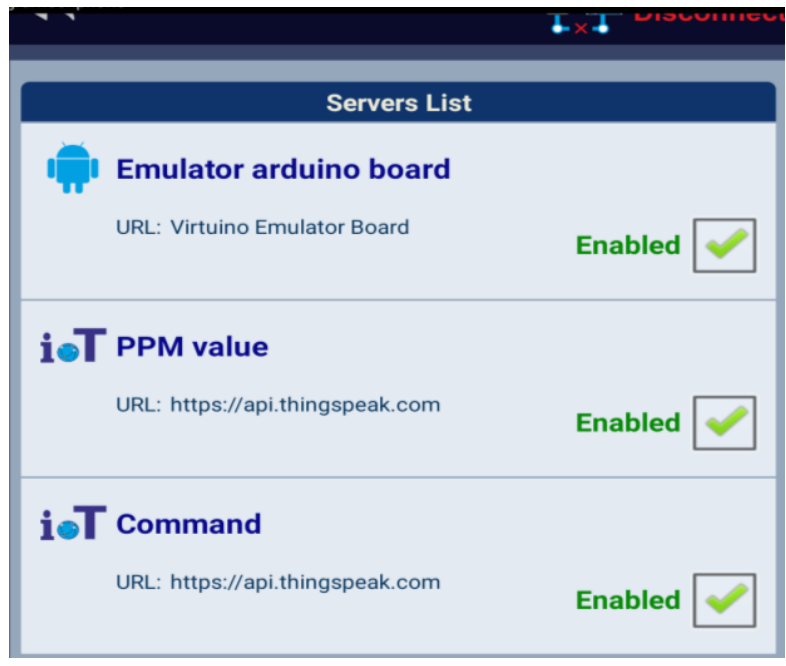

Figure 17. Connect/ disconnect interface of the mobile app

\section{Online Server Interface}

The server to monitor the IoT data used in this setup is 'ThingSpeak' which is a free service provided by MATLAB for students and experimental purposes. Users have to open a channel before the integration of the data storage. Our channel was created as the following.

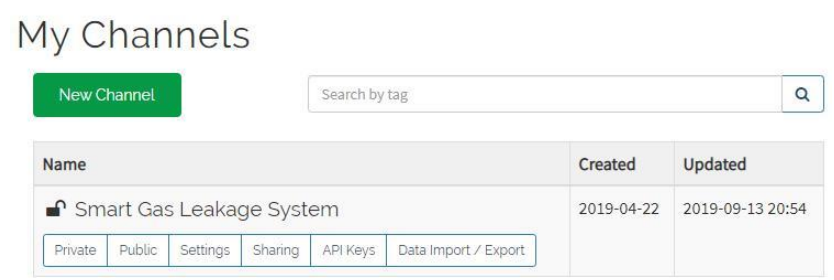

Figure 18. ThingSpeak channel for IoT data monitoring

If the controller is connected to the power, the sensors can read data from the environment where it is set. A dataset or reading of LPG PPM, Humidity, and Temperature and relay state in our server has been represented in Figure 19-22.

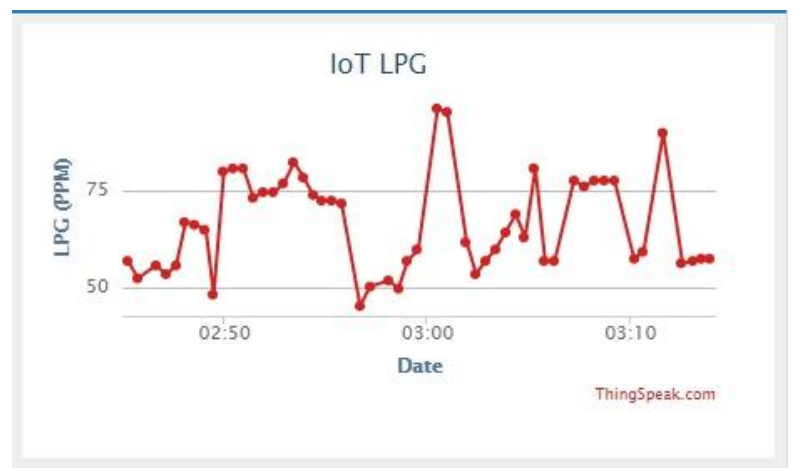

Figure 19. LPG ppm value reading on the cloud server

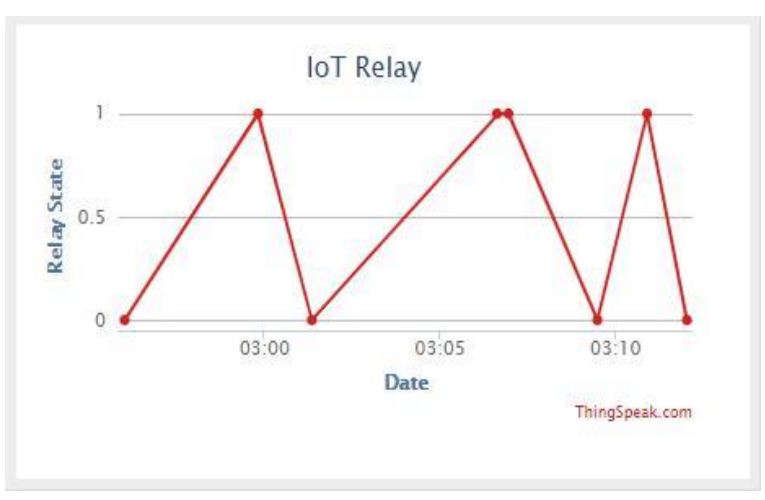

Figure 20. Relay stat at a different time on the cloud server.

Figure 19 describes the LPG concentration of the environment where it was set at different times. Sometimes, gas lighters were used to raise the LPG concentration and to check whether the data was correct or not. The relay state in the following Figure 20 can describe the state of the relay concerning time. $\mathrm{o}$ means relay is off and 1 means relay is on. The mobile application is suitable for home application and the online server is suitable for industrial application.

If the LPG ppm value exceeds the pre-set threshold value, then the actuators will be activated automatically. That means, the solenoid valve of the LPG cylinder is on and $\mathrm{CO} 2$ cylinder is off. After the activation, the LPG cylinder solenoid valve will be closed and the $\mathrm{CO} 2$ cylinder will diffuse gas by turning on the solenoid valve. This is the working logic of a single relay system where only two actuators exist.

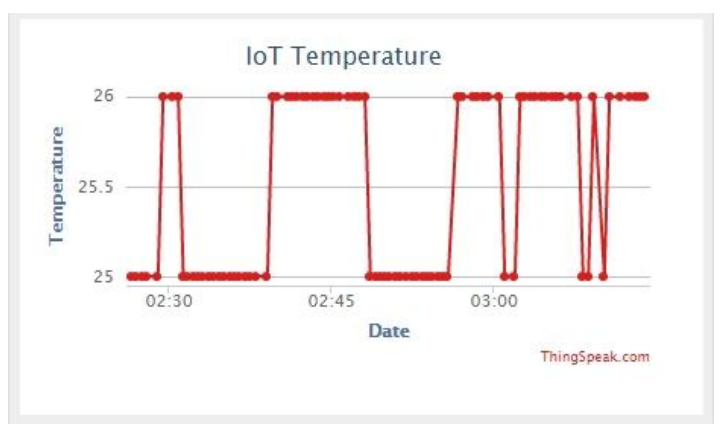

Figure 21. The temperature reading on the cloud server 


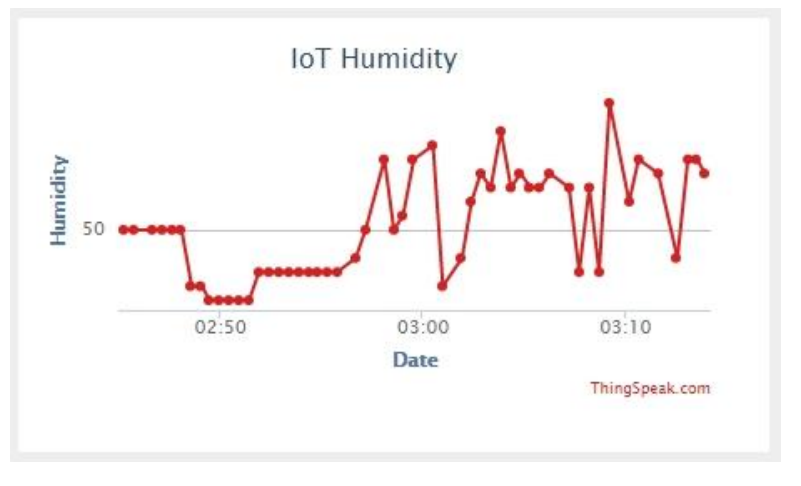

Figure 22. Humidity value reading on the cloud server

\section{B. SWOT Analysis}

The system has many advantages but also has some weakness. The SWOT analysis of this system:

\section{Strength:}

- Continuous remote monitoring capacity

- Automatic leakage detection

- Automatic and manual 'ON'/ 'OFF' system of the valves

- Enables a cyber-physical system

- Eliminates human effort in leakage detection and firefighting

\section{Weakness:}

- Setup cost may be high for Industrial System

- Program handling might be difficult

- Continuous electricity and internet connection is required

\section{Opportunities:}

- Enables rapid action in fire-fighting and LPG leakage detection

- Losses due to fire accident can be reduced

- Death and injuries due to fire accident will be reduced

- $\quad$ Rapid suppression of fire will be possible by shutting down the source

\section{Threats:}

- Cyber-attack may occur by hackers and they can spread LPG and occur fire accident

- Fire extinguisher cylinders should be refilled after expiration of validity dates
- $\quad$ Cybersecurity must be strong

\section{CONCLUSION}

A lot of people die every year due to fire accidents both in residential houses and industries. As LPG is widely used in most ohouses, industries, hospitals, vehicles and so many places, a proper safety system is required to eliminate or reduce the hazard. This automated LPG detection and fire extinguisher system can not only work on LPG fire but also on other types of fire sources like an electric short circuit, explosion etc. There are mainly five types of fire extinguishers: water, foam, dry powder, $\mathrm{CO}_{2}$ and dry chemical and all are available commercially in cylinders. The conventional valves can be replaced by solenoid valves and can easily connect to this system. All the solenoid valves can easily be controlled individually by connection to independent relays. The main purpose of implementing Industry 4.0 is to eliminate human effort in fire-fighting so that lives can be saved and also the reduction of injuries. The instant automatic action will also activate the valves automatically to close the leakage source that will help the rapid suppression of fire. The main challenge to implementing industry 4.0 is to develop the server for data monitoring and control it. Proper training is required to operate and maintain this system. A major limitation of this research was the server that used as a free version for trial purpose and it has a delay period of 5 seconds after receiving the signal to transmit to the actuator.

\section{ACKNOWLEDGEMENT}

The authors are very grateful to Prof. Dr Md. Mosharraf Hossain (Dean, Faculty of Mechanical Engineering, RUET) and Prof. Dr Mhia Md. Zaglul Shahadat (Professor, Dept. of Mechanical Engineering, RUET) for their Technical cooperation and instructions.

\section{REFERENCES}

Atzori, L, Iera, A, \& Morabito, G 2010, 'The internet of things: a survey', Computer Networks, vol. 54, no. 15, pp. 2787-
2805. doi: 10.1016/j.comnet.2010.05.010.

Bartko, JJ \& Carpenter, WT 1976, 'On the methods and theory 
of reliability', Journal of Nervous and Mental Disease, vol. 163, no. 5, pp. 307-317. doi: 10.1097/00005053197611000-00003.

Chengjun, D, Ximao, L \& Ping, D 2011, 'Development on gas leak detection and location system based on wireless sensor networks', in 2011: Third International Conference on Measuring Technology and Mechatronics Automation, IEEE, vol. 1, 1067-1070. doi: 10.1109/ICMTMA.2011.267.

Dewi, L \& Somantri, Y 2018, 'Wireless sensor network on LPG gas leak detection and automatic gas regulator system using Arduino', in IOP Conference Series: Materials Science and Engineering, vol. 384, no. 1, pp. 012064. doi: 10.1088/1757899X/384/1/012064.

Dhawale, DS, Dubal, DP, More, AM, Gujar, TP \& Lokhande, CD 2010, 'Room temperature liquefied petroleum gas (LPG) sensor', Sensors and Actuators, B: Chemical, vol. 147, no. 2, pp. 488-494. doi: 10.1016/j.snb.2010.02.063.

Ghayyur, S, Chen, Y, Yus, R, Machanavajjhala, A, Hay, M, Miklau, G \& Mehrotra, S 2018, 'IoT-Detective: analyzing IoT data under differential privacy', in Proceedings of the ACM SIGMOD International Conference on Management of Data, pp. 1725-1728. doi: 10.1145/3183713.3193571.

Hasan, MZ, Mallik, A \& Tsou, JC 2020, 'Learning method design for engineering students to be prepared for industry 4.0: a Kaizen approach', Higher Education, Skills and Work-Based Learning. doi: 10.1108/HESWBL-07-20190098.

Keshamoni, K \& Hemanth, S 2017, 'Smart gas level monitoring, booking \& gas leakage detector over IoT', in Proceedings - 7th IEEE International Advanced Computing Conference, IACC 2017, pp. 330-332. doi: 10.1109/IACC.2017.0078.

Khan, R, Khan, SU, Zaheer, R \& Khan, S 2012, 'Future internet: the internet of things architecture, possible applications and key challenges', in Proceedings - 1oth International Conference on Frontiers of Information Technology, FIT 2012, pp. 257-260. doi: 10.1109/FIT.2012.53.

Mallik, A, Ahmed, S, Hossain, GMM \& Rahman, MR 2020, 'IoT utilized gas-leakage monitoring system with adaptive controls applicable to dual fuel powered Naval vessels/ships : development \& implementation', Cybernetics and Information Technologies, vol. 20, no. 1, pp. 138-155. doi: 10.2478/cait-2020-0010.

Mallik, A, Hossain, SA, Karim, A Bin \& Hasan, SM 2019, 'Development of LOCAL-IP based environmental condition monitoring using wireless sensor network', International
Journal of Sensors, Wireless Communications and Control, vol. 9, no. 4, pp. 454-461. doi: 10.2174/2210327909666190208161832.

Minerva, R, Biru, A \& Rotondi, D 2015, 'Towards a definition of the Internet of Things (IoT)', in IEEE Internet of Things, vol. 1, no. 1, pp. 1-86. doi: 10.5923/j.ijit.20150401.01.

Moktadir, MA, Ali, SM, Kusi-Sarpong, S \& Shaikh, MAA 2018, 'Assessing challenges for implementing industry 4.0: implications for process safety and environmental protection', Process Safety and Environmental Protection, vol. 117, pp. 730-741. doi: 10.1016/j.psep.2018.04.020.

Naess, A, Leira, BJ \& Batsevych, O 2009, 'System reliability analysis by enhanced Monte Carlo simulation', Structural Safety, vol. 31, no. 5, pp. 349-355. doi: 10.1016/j.strusafe.2009.02.004.

Oesterreich, TD \& Teuteberg, F 2016, 'Understanding the implications of digitisation and automation in the context of industry 4.0: a triangulation approach and elements of a research agenda for the construction industry', Computers in Industry, vol. 83, pp. 121-139. doi: 10.1016/j.compind.2016.09.006.

Ray, PP 2018, 'A survey on Internet of Things architectures', Journal of King Saud University - Computer and Information Sciences, vol. 30, pp. 291-319. doi: 10.1016/j.jksuci.2016.10.003.

Savitha, N \& Malathi, S 2018, 'A survey on fire safety measures for industry safety using IoT', in Proceedings of the 3 rd International Conference on Communication and Electronics Systems, ICCES 2018, pp. 1199-1205. doi: 10.1109/CESYS.2018.8723930.

Shahadat, M, Mallik, A \& Islam, M 2019, 'Development of an automated gas-leakage monitoring system with feedback and feedforward control by utilizing IoT', Facta Universitatis - Series: Electronics and Energetics, vol. 32, no. 4, pp. 615-631. doi: 10.2298/fuee1904615s.

Trappey, AJC, Trappey, CV, Fan, CY, Hsu, APT, Li, XK \& Lee, IJY 2017, 'IoT patent roadmap for smart logistic service provision in the context of industry 4.0', Journal of the Chinese Institute of Engineers, vol. 40, no. 7, pp. 593-602. doi: 10.1080/02533839.2017.1362325.

Weyer, S, Schmitt, M, Ohmer, M \& Gorecky, D 2015, 'Towards industry 4.0 - standardization as the crucial challenge for highly modular, multi-vendor production systems', IFACPapersOnLine, vol. 28, no. 3, pp. 579-584. doi: 10.1016/j.ifacol.2015.06.143.

$\mathrm{Xu}, \mathrm{LD}, \mathrm{Xu}, \mathrm{EL} \& \mathrm{Li}, \mathrm{L} 2 \mathrm{2018}$, 'Industry 4.0: state of the art and future trends', International Journal of Production 
Research, vol. 56, no. 8, pp. 2941-2962. doi: 10.1080/00207543.2018.1444806.

Zawra, LM, Mansour, HA, Eldin, AT \& Messiha, NW 2018, 'Utilizing the internet of things (IoT) technologies in the implementation of Industry 4.0', Advances in Intelligent Systems and Computing, vol. 639, pp. 798-808. doi: 10.1007/978-3-319-64861-3_75.

Zhu, Q, Wang, R, Chen, Q, Liu, Y \& Qin, W 2010, 'IoT gateway: bridging wireless sensor networks into Internet of Things', in Proceedings - IEEE/IFIP International Conference on Embedded and Ubiquitous Computing, EUC 2010, pp. 347-352. doi: 10.1109/EUC.2010.58. 